\title{
Imaginación proyectada: nodos de transnacionalidad en los festivales de cine
}

\author{
Juan Manuel González Fernández ${ }^{1}$ \\ Universidad de Monterrey
}

\section{RESUMEN}

A partir del concepto de los mundos imaginados que propone Appadurai en Modernity at Large (1996), es propósito de este ensayo acercarse hacia la descripción de cómo los festivales de cine gestan nodos transnacionales que permiten a sus asistentes, mediante proyecciones de películas provenientes de diversas naciones y los diálogos entre realizadores y el público, la participación en esferas públicas espontáneas y efímeras que generan oportunidades de crear o modelar sus imaginarios individuales y colectivos sobre los contextos, experiencias y retos que enfrentan los seres humanos alrededor del planeta. Así, se propone en la conclusión, contribuyen a la formación de mundos imaginarios compartidos que brindan a los individuos opciones para la construcción de sus biografías con una visión más cosmopolita, definida por la corresponsabilidad entre todos y cada uno de los seres humanos.

Palabras clave: Festivales de cine, transnacionalidad, cinemascapes, imaginación, identidad

\begin{abstract}
Using the concept of imagined worlds proposed by Appadurai in Modernity at Large (1996), as a point of departure, it is the purpose of this essay to approach the description of how film festivals create transnational nodes that allow their attendees, through projections of films from diverse nations and dialogues between filmmakers and the public, participation in spontaneous and ephemeral public spheres that generate opportunities to create or model their individual and collective imaginaries about the contexts, experiences and challenges facing human beings around the planet. Thus, it is proposed in the conclusion, they contribute to the formation of shared imaginary worlds that provide indi-
\end{abstract}

${ }^{1}$ Master of Fine Arts por el Art Center College of Design. Profesor y director del programa de Licenciado en Ciencias de la Información y Comunicación en la Universidad de Monterrey. Correo electrónico: juan.gonzalezf@udem.edu 
viduals with options for building their biographies with a more cosmopolitan vision, defined by the co-responsibility between each and every buman being.

Keywords: Film festivals, transnationalism, cinemascapes, imagination, identity 


\section{INTRODUCCIÓN}

La condición transnacional del cine contemporáneo plantea una gran cantidad de problemas que son material de gran interés para el estudio humanista.

El dinamismo de los flujos globales, tanto de personas como de información dan pie a numerosas posibilidades de producción, distribución y consumo cinematográfico que en conjunto integran una compleja red de significantes y significados audiovisuales que inciden en la creación de imaginarios individuales y colectivos (Appadurai, 1996).

Esta red interconecta a múltiples actores que ejercen distintos niveles de influencia. Por una parte está Hollywood como concepto hipostasiado en las majors o principales productoras y distribuidoras de películas, que ejerce una fuerza imperialista y avasalladora que en gran parte del mundo representa el mayor porcentaje de exhibición y consumo local.

Por otro, están las cinematografías locales y diaspóricas, contrahegemónicas, que tejen su propia red para encontrar oportunidades de impulsar sus contribuciones a la creación de imaginarios alternativos en el propio territorio o en comunidades desterritorializadas (Ezra y Rowden, 2006). Y en medio se encuentran numerosos agentes que impulsan de acuerdo a su perspectiva local fibras que dan forma $y$ des/estabilidad a la red.

Entre estos agentes se encuentran los festivales de cine, que a través de sus actividades generan nodos de transnacionalidad que mediante el intercambio de significados entre cineastas y públicos pueden moldear y enriquecer los imaginarios individuales y colectivos impulsando a los locales hacia una visión más cosmopolita como la entiende Kwame Anthony Appiah (2006).

La imaginación, argumenta Arjun Appadurai (1996) ha tomado un nuevo rol en la vida de las personas gracias a un cambio en el orden cultural global que ha sido creado por el cine, la televisión y el video.

No hace mucho, las personas tenían "un conjunto relativamente finito de vidas posibles" que dictaban las tradiciones, y la imaginación estaba reservada para "lugares o momentos especiales” (p. 53).

Sin embargo, en la actualidad "las biografías de las personas ordinarias son construcciones (o fabricaciones) en las cuales la imaginación juega un papel importante" (p.54). Así, afirma Appadurai, se desarrollan una variedad de comunidades imaginadas, como lo había sugerido Anderson (1993).

Dando primacía a los mundos imaginados que propone Appadurai en Modernity at 
Large (1996), es propósito de este ensayo acercarse hacia la descripción de cómo los nodos transnacionales que los festivales de cine ofrecen a sus asistentes permite la participación en esferas públicas espontáneas y efímeras que ofrecen oportunidades de crear o modelar sus imaginarios.

\section{CONCEPTOS TEÓRICOS}

Arjun Appadurai en Modernity at Large (1996) propone una teoría para estudiar la modernidad que rompe "con todo tipo de pasados" y “...toma los medios de comunicación y la migración como sus dos principales, e interconectados, distintivos, explorando su efecto conjunto en el trabajo de la imaginación como una característica constitutiva de la subjetividad moderna" (p. 3). Appadurai afirma que "ha habido un cambio en décadas recientes, que se alza sobre los cambios tecnológicos del último siglo, en el que la imaginación se ha convertido en un hecho social colectivo" (1996, p. 5).

Para defender su postura, que remarca como transnacional, o incluso postnacional, Appadurai argumenta que la imaginación ya no es dominio exclusivo del "espacio expresivo del arte, el mito y el ritual", que ahora "es un escenario para la acción, no solamente para el escape"; y que los medios de comunicación posibilitan la creación de grupos que "imaginan y sienten juntos" (p. 7). Especialmente poderosos considera al cine y al video, capaces de formar fraternidades alrededor de deidades, políticos, deportistas, y otros líderes que pueden pasar de la imaginación colectiva a la acción.

Para Appadurai, la imaginación es una práctica social que reúne la idea de la imagen como la entiende la escuela de Frankfurt, las comunidades imaginarias de Anderson, y la idea francesa de lo imaginaire "como un paisaje construido de aspiraciones colectivas" (1996, p. 31). "La imaginación hoy es central a todas las formas de agencia, es en sí misma un hecho social y es un componente clave del nuevo orden mundial" concluye Appadurai.

Son cinco las dimensiones de los flujos globales culturales que propone Appadurai (1996) para atender las que entiende como disyunciones fundamentales entre la economía, la cultura, y la política.

Estas dimensiones, que presenta como paisajes (por su terminación en inglés, scape) pretenden ser un marco de referencia para "explorar dichas disyunturas" (1996, p. 33) y son los (a) ethnoscapes, el "paisaje de las personas que constituyen el mundo cambiante en el que vivimos; el (b) technoscape, la "configuración global, siempre fluida, de la tecnología" y 
el hecho de que ahora viaja a velocidades altas cruzando fronteras antes impenetrables; los (c) financescapes, la "disposición del capital global que hoy es un paisaje más misterioso, rápido y difícil de seguir"; los (d) mediascapes, que se refieren tanto a la "capacidad electrónica de producir y diseminar información" como a las "imágenes del mundo creadas por estos medios"; y los (e) ideoscapes, que también son imágenes pero "a menudo directamente políticas y que frecuentemente tienen que ver con las ideologías de los estados o las contraideologías de movimientos explícitamente orientados para tomar el poder estatal".

Para Appadurai, "la velocidad, el tamaño y el volumen de estos flujos son tan grandes ahora que las disyunturas se han vuelto centrales para la política de la cultura global" (1996, p. 36) y propone un enfoque de la teoría del caos para poder preguntarse no solamente cómo todas las formas complejas que constituyen las formas culturales se sostienen en un sistema estable, sino también cuáles son sus dinámicas. Quizá la principal falla en el planteamiento de Appadurai, radica en su predicción equívoca de la desaparición del Estado-nación.

La historia de los últimos 20 años ha demostrado que al contrario, múltiples nacionalismos han surgido y demandado su propio estado, y los Estados-nación, han buscado reafirmar su independencia, como lo demuestran el Brexit del Reino Unido y la victoria de Donald Trump en las elecciones presidenciales de Estados Unidos del 2016, ambas resultado de una búsqueda reterritorializadora y reafirmante del Estado-nación.

Sin embargo, su modelo de los flujos globales ha tenido un impacto importante en otras disciplinas, particularmente aquellas que se ven partícipes de la teoría.

Shahab Esfandiary (2012) retoma el modelo de los flujos globales de Appadurai para aplicarlo al estudio del cine, construyendo el término cinemascapes, a los que responsabiliza de la diseminación de imágenes y narrativas por todo el mundo.

Este término está inspirado en la propuesta de Noël Carrol, el culturescape, que, con sus propios "juegos de lenguaje y redes de comunicación, distribución y recepción” permite el surgimiento de un "nuevo 'mundo del arte integrado, interconectado y transnacional"' (en Esfandiary, 2012, p. 26).

Este nuevo paisaje cinematográfico incluye, como se menciona en la introducción a una gran cantidad de agentes, que empujan y estiran en todos los sentidos. Sin embargo, en este ensayo nos enfocaremos exclusivamente en los festivales de cine y los nodos transnacionales que se gestan en ellos. 
Llamaremos nodos a los puntos de convergencia donde se reúnen expresiones cinematográficas, cineastas, empresarios del cine y públicos para generar un evento fílmico; y los llamaremos transnacionales puesto que abren espacios de interacción para los actores antes mencionados (muchas veces provenientes de distintas naciones ellos mismos) donde las películas, de manera virtual, generan un portal hacia diversas naciones en la sala de proyecciones. Estos nodos transnacionales, a lo largo del tiempo y el espacio, forjan redes sociales globales que tienen la posibilidad de ser descritas mediante el análisis de redes sociales.

Efectivamente, estos nodos no son exclusivos de los festivales de cine, pueden darse de manera aislada en funciones especiales de cine, cinematecas, o ambientes universitarios, pero los festivales de cine operan como esferas eventos que se construyen a partir de los múltiples discursos que se gestan en ellos y que tienen el poder de transformar su ámbito como lo proponen Hardy y Maguire (2010). Así, podemos entenderlos como eventos especiales con un gran poder de impactar la imaginación colectiva como lo entiende Appadurai (1996).

\section{EL PAISAJE CINEMATOGRÁFICO}

Fue la visión de sus inventores la que lanzó al cine en un proceso transnacional desde sus inicios. Para entender el fenómeno de los festivales de cine resulta pertinente compararlo con la difusión global del original cinematógrafo de los Hermanos Lumière, aparato que si bien no fue el único invento que trajo la experiencia de las imágenes en movimiento, sí fue el que definió el inicio de su historia como medio público y colectivo a través de la diseminación de la experiencia social de un grupo de desconocidos que se reúnen en la oscuridad de una sala para ver el cine.

Los hermanos Lumière, inventores del cinematógrafo, durante los tres siguientes años a la presentación de su invento el 28 de diciembre de 1895, se dedicaron a entrenar camarógrafos que Erik Barnouw (1993, p. 9) llama los Lumière world travelers.

Estos camarógrafos viajaron, filmando y exhibiendo películas por toda Europa, llegando incluso a presentar el cinematógrafo al zar de Rusia, y después por todo el mundo.

El emprendimiento de los Lumière era doblemente exitoso, por un lado los programas extranjeros y locales resultaron altamente atractivos en los países que visitaban y por otro la llegada del material del exterior a Francia, enriqueció el catálogo de películas de la compañía. ${ }^{2}$

${ }^{2}$ Barnouw (1993) asegura que dentro de los primeros seis meses de la presentación del cinematógrafo en París los operadores Lumière habían lanzado el invento en "Ingla- 
Para finales de 1897 más de cien operadores Lumière recorrían el planeta y "el cinématographe ya estaba brindando a sus públicos un sentido sin precedentes de ver el mundo" (Barnouw, 1993, p. 13). La Sociedad Lumière tejió así una importante red transnacional a través de la cual profesionales franceses viajaban a remotos sitios del planeta para establecer espacios de proyección, filmar nuevos títulos para el catálogo y dejar en el sitio el cinematógrafo para que sus nuevos explotadores adquirieran películas del catálogo Lumière que traían nuevas vistas de lejanos territorios.

Esta capacidad de acercar lo lejano insertó al cine, desde sus orígenes, en el camino de la globalización y a través de los viajes de los camarógrafos y sus colaboraciones locales, en un proceso transnacional que sembraba las semillas del cosmopolitismo.

El ejemplo de la llegada del cinematógrafo a México nos da una idea de cómo sucedió alrededor del mundo. Aurelio de los Reyes (1995) relata que Gabriel Veyre, camarógrafo Lumière, y Claude Fernand Bon Bernard, empresario concesionario, llegaron a México el 24 de julio de 1896 para instalarse por una temporada en la Ciudad de México y explotar

terra, Bélgica, Holanda, Alemania, Austria, Hungría, Suiza, España, Italia, Serbia, Rusia, Suecia, Estados Unidos $-\mathrm{y}$ poco tiempo después en Algeria, Túnez, Egipto, Turquía, India, Australia, Indochina, Japón y México-”." la exhibición y producción de filmes, iniciando proyecciones privadas el 6 de agosto y públicas el día 15.

No se sabe el momento exacto en que se realizó la primera película en suelo mexicano, pero de los Reyes reporta que en una carta de Veyre se afirma que unos días antes del 16 de agosto del mismo año se había filmado al presidente Porfirio Díaz (de los Reyes, 1995, p. 127). Permanecieron en el país hasta enero de 1897, cuando Veyre regresó a Francia y Bernard a Argentina quedándose el cinematógrafo en México.

Cada una de las funciones del original cinematógrafo generaba un nodo de transnacionalidad, donde por primera vez en México se podían conocer, ampliadas sobre una pantalla y con movimiento realista, imágenes de remotas naciones que permitían al espectador imaginar uno o más mundos. Appadurai (1996, p. 33) define que los paisajes de su modelo de los flujos globales constituyen las piezas de lo que llama mundos imaginados. Los mundos imaginados, nos dice, son "los múltiples mundos que se constituyen por las imaginaciones históricamente posicionadas de las personas y los grupos que se extienden a lo largo del mundo" (p. 33). Hoy, en la era de la hiperconectividad, quizá resulta difícil imaginar la importancia de estos nodos donde a 
través de la imagen en movimiento confluía el mundo entero. Es propuesta de este ensayo, que los festivales de cine ofrecen una experiencia equivalente al presentar un programa de películas que se alejan de la ola hegemónica del cine hollywoodense y ofrecen ventanas a múltiples realidades nacionales. Así como sucedía en las primeras funciones del cinematógrafo, en los festivales de cine es posible para los participantes modelar sus mundos imaginados.

\section{LOS FESTIVALES DE CINE Y LOS NODOS DE TRANSNACIONALIDAD}

Los festivales de cine representan espacios de migración sin desplazamiento y de reterritorialización para los desplazados, donde las propuestas audiovisuales y la presencia de los cineastas permiten la generación de espacios de excepción donde a través de la interacción transnacional se modelan los imaginarios. En cada festival o en los circuitos de festivales, como se explicará más adelante, se manifiestan las disyunturas que Appadurai (1996) identifica entre las cinco dimensiones de los flujos culturales globales, y además, se desarrolla dentro de la dimensión del cinemascape que propone Esfandiary (2012).

El primer festival de cine, la "Exposición de arte cinematográfico" ahora conocida co- mo el Festival de Cine de Venecia, se realizó en 1932 como parte de la Bienal de Venecia (La Biennale di Venezia, s.f.) Poco después, faltando poco tiempo para su inauguración, el Festival de Cannes pospuso su primera edición en 1939 hasta la posguerra, cuando se inauguró el 20 de septiembre de 1946 (Festival de Cannes, s.f.) y el Festival de Cine de Berlín le siguió en junio de 1951 (Internationale Filmfestspiele Berlin, s.f.). Estos tres festivales, hasta hoy en día los más importantes del mundo, tienen en sus orígenes intenciones muy específicas. Marijke de Valck (2007) asegura que fue "la específica situación geopolítica europea en el periodo que precedió a la Segunda Guerra Mundial y la era inmediata de posguerra la que reunió los incentivos necesarios para iniciar el desarrollo" de los festivales de cine (traducción propia).

Habrá que considerar que el Festival de Cannes fue una estrategia de Francia, el Reino Unido y Estados Unidos para hacer frente al Festival de Venecia, que cada día era más político y se enfocaba hacia la promoción del fascismo (Ronk y Rothman, 2013, mayo 13). A su vez, el Festival de Cine de Berlín, hoy conocido como la Berlinale, surgió para "satisfacer la añoranza de la ciudad de reconocimiento y atención. Y al mismo tiempo el festival tenía la intención de hacer una declaración 
política y servir de 'escaparate del mundo libre' en la ciudad dividida" (traducción propia, Internationale Filmfestspiele Berlin, s.f.).

Aunque este origen político de los festivales, resulta innegable, estos y muchos otros eventos similares han buscado establecerse como espacios temporales para la reunión de películas, públicos y creadores y es el mismo Festival de Cannes el que destaca en su página web, referente a su fundación, una cita de Jean Cocteau: "El Festival es una tierra de nadie apolítica, un microcosmos de lo que el mundo sería si las personas pudieran tener contacto directo una con la otra y hablaran el mismo idioma" (traducción propia, Festival de Cannes, s.f.). Esta frase, nos recuerda mucho al concepto de la "esfera pública" que Jürgen Habermas (1991) establece en 1962.

En México, de acuerdo al Anuario estadístico de cine mexicano 2016, publicado por el Instituto Mexicano de Cinematografía (2017), existen 130 festivales de cine. Estos festivales tienen diversas formas y propósitos. Algunos están orientados al público y prácticamente no tienen participación de la industria, como la Muestra Internacional de Cine de la Cineteca Nacional, el festival Mórbido, o el Tour de Cine Francés; otros tienen agendas políticas particulares como Ecofilm Festival o el Festival Queer Monterrey; y otros, que en mayor o menor grado, buscan ser un punto de encuentro para la comunidad de creadores audiovisuales.

Los festivales con agendas políticas buscan incidir en su área temática mientras que los festivales "de industria" en la actividad audiovisual regional o nacional ya sea en el espacio creativo o institucional.

Los 130 festivales de cine que el IMCINE reporta que ocurren en México, son parte de un ecosistema donde todos están interrelacionados por su ubicación en el calendario o su identidad. Actualmente, al hablar de los festivales en el mundo, se tiende a hablar de un "circuito" de festivales.

Rhyne (2009, p. 9) plantea como la tesis de su artículo que "el circuito de festivales se mantiene a través de la articulación discursiva y económica de una industria cultural discreta y nueva" y que "se sostiene por las distintas partes interesadas — cineastas y estudios, periodistas y agentes de prensa, profesionales y programadores, consejos locales de cultura y agencias supranacionales, consejos turísticos, cinéfilos y otros- que tienen intereses particulares en ver que la red se prolifere".

Es difícil delimitar las inclusiones y exclusiones de este circuito de festivales, pues se estima que anualmente hay alrededor de tres mil festivales de cine activos, de nueve mil 706 
que han tenido al menos una edición entre 2000 y 2013 (Follows, 2013). Así que quizá sea más sencillo hablar de "circuitos" de festivales de cine.

El más grande, el de los festivales "Clase A" acreditados por la FIAPF (Federación Internacional de Asociaciones de Productores de Cine) reúne a 15 festivales competitivos (FIAPF, 2016) entre los que se encuentran Cannes, Berlín, Venecia, San Sebastián y Mar del Plata. Pero junto a éste hay una gran variedad de circuitos no-especializados y especializados que recorren el calendario de festivales.

Así, podríamos hablar del "circuito de festivales de cine en México" del que evidentemente serían parte Guadalajara, Morelia, Guanajuato, Monterrey, Riviera Maya, FICUNAM, DocsDF y muchos más de los que se reporta que ocurren en el país.

¿CÓMO OPERAN LOS FESTIVALES DE CINE COMO PARTE DE LOS FLUJOS CULTURALES GLOBALES Y DE QUÉ MANERA SE GESTAN LOS NODOS DE TRANSNACIONALIDAD EN SU ÁMBITO?

Se ha hablado de diferentes circuitos de festivales. A su vez, dentro de ellos, existen distintos tipos de festivales de cine, que definen su identidad de acuerdo a diferenciadores como el tipo y duración de las películas que proyectan, su atención a temas o géneros específicos, su vinculación a públicos especializados o su tamaño y presupuesto.

Estos diferenciadores, entre muchos más, generan distintos balances en el modelo de los flujos globales de Appadurai (1996).

Un festival como Cannes, tiene peso importante en todas las dimensiones, desde la financiera hasta la ideológica, sin embargo, festivales especializados como aquellos dedicados al cine feminista, el cine de migrantes, el cine sobre ecología, encuentran la balanza de las dimensiones canteada de maneras distintas.

Aquí, es pertinente detenerse en los cinemascapes de Esfandiary (2012), quien nos dice:

La conceptualización de Appadurai de los mediascapes y los ethnoscapes es directamente relevante para el estudio de la globalización y el cine nacional. La primera, involucra tanto la difusión de las tecnologías de la producción de medios (incluyendo al cine) y la creación de "amplios y complejos repertorios" de imágenes y narrativas acerca del mundo. En este sentido, se puede investigar la forma en la que lo que podemos llamar los cinemascapes están involucradas en crear y exhibir imágenes del mundo y de otras naciones y culturas (p. 35). 
Los ethnoscapes son particularmente relevantes para estudiar la vinculación de los festivales de cine con los cineastas que producen en la diáspora —el cine acentuado de Hamid Naficy (2001) — o las comunidades migratorias que consumen productos que reciben de sus naciones originarias.

Diana Iordanova y Ruby Cheung (2010) editaron el segundo número del Film Festival Yearbook, titulado Film Festivals and Imagined Communities para el cual solicitaron artículos que explorasen los "festivales relacionados con las diásporas y canales diaspóricos de distribución de películas" (p. 2).

Así, el volumen incluye reflexiones sobre festivales de cine africano fuera de África, sobre el Festival de Cine del Sahara, sobre el Festival de Cine de Trabajadores Migrantes en Corea del Sur, o sobre festivales de la diáspora asiática en San Francisco.

Estos festivales, como muchos otros, contribuyen a la creación de imaginarios colectivos a través de la confluencia de películas, cineastas y públicos de diversas nacionalidades en espacios definidos.

Cindy Hing-Yuk Wong (2016), explica:

A menudo en el contexto de un festival, las películas se exhiben con directores, actores, productores y cinefotógrafos respondiendo preguntas de la prensa y el público en general. Esta intimidad, que rara vez se encuentra en una función general en un cine comercial, evoca las visiones de Hansen y Warner de esferas públicas transitorias pero intensas donde personas, que rara vez se conocen previamente, pueden estar en un mismo espacio para discutir (p. 86).

Si se revisan los programas de recientes festivales de cine en México, encontraremos que están constituidos por una colección de eventos individuales o concatenados que se presentan, concentrados una vez al año, en una fecha y horario determinados

Estos eventos, en su forma más básica, son las exhibiciones de películas, que suelen ser el centro de la mayoría de los festivales de cine. Por ejemplo, el Festival Internacional de Cine UNAM (s.f.) menciona en su sitio de internet que en su edición 2016, se sostuvieron 155 proyecciones de películas de 99 títulos distintos provenientes de 33 países, ante más de 18 mil asistentes. En estas funciones estuvieron presentes 70 directores de cine, que muy probablemente presentaron sus películas y participaron en sesiones de preguntas y respuestas.

Estas esferas públicas transitorias, constituyen nodos transnacionales que impulsan, a través de las expresiones audiovisuales y el 
diálogo, la formación de mundos imaginarios diversos.

DocsMx, el Festival Internacional de Cine Documental de la Ciudad de México (2016), presentó en su decimoprimera edición, 145 realizaciones provenientes de 45 países, presentando versiones de la realidad provenientes de naciones en los cinco continentes. Los espectadores, así, tuvieron la experiencia de ver documentales de Cuba, Francia, Nicaragua, Nepal, Rusia, Palestina y México, entre muchos otros orígenes.

Entre los títulos proyectados están, por ejemplo, el largometraje suizo Raving Iran, de la directora Susanne Regina Meures, que narra la historia de Anoosh y Arash, dos jóvenes de Teherán que organizan raves ilegales; la cinta griega Próxima estación: Utopía, del director Apostolos Karakasis, sobre la toma de control por los trabajadores de una fábrica en bancarrota; o el cortometraje de Arjun Talwar y Oliver Krüger El nido que narra la historia de una familia de pastores nómadas en el Sahara. Así como estos tres ejemplos, el público asistente a DocsMx, que asciende a 400 mil personas en su primera década, se enfrenta con olas de transnacionalidad que en estos espacios les permiten moldear o crear imaginarios acerca de cómo, como afirma Appadurai, construir sus vidas.

\section{CONCLUSIÓN}

A nivel mundial son millones de personas las que participan en los miles de festivales de cine que se realizan cada año. Como hemos visto, las funciones de cine se convierten en espacios de discusión que permiten el conocimiento y diálogo entre desconocidos, sean miembros del público, de la prensa o de la industria del cine. Los festivales de cine, de acuerdo a su identidad, pueden tener distintos balances de las cinco dimensiones que generan disyunturas en los flujos globales aunque su agencia principal provenga del mediascape. Festivales clase "A" como Cannes, suelen ser exclusivos, con los pies bien hundidos en los financescapes de la industria audiovisual, aunque Berlín que pertenece a la misma categoría de festivales es un festival con mayor apertura y un vuelco importante hacia los ethnoscapes y los ideoscapes. Mientras tanto, pequeños festivales como los que destacan Iordanova y Cheung (2010) suelen estar mucho más cercanos a sus públicos y participantes.

Si bien el cine no se ha podido liberar del yugo del Estado-nación, ya que se encuentra anclado por la gran cantidad de requisitos legales y comerciales que le obligan a portar certificados de origen, la exhibición de películas de múltiples nacionalidades en festivales de cine a nivel mundial genera nodos de transna- 
cionalidad que impulsan el modelado o formación de imaginarios individuales y colectivos sobre los contextos, experiencias y retos que enfrentan los seres humanos alrededor del planeta, contribuyendo a la formación de mundos imaginarios compartidos como los propone Arjun Appadurai (1996).

Este ejercicio, que como Barnouw (1993) dijo de los primeros espectadores del cine, "brinda un sentido sin precedentes de ver el mundo" (itálicas propias), de imaginación proyectada, resulta de gran importancia para la formación de ciudadanos cosmopolitas, pues como dice Kwame Anthony Appiah (2006) "ninguna lealtad local jamás podrá justificar el olvido de que cada ser humano tiene responsabilidades para cada otro". 


\section{FUENTES CONSULTADAS}

Anderson, B. (1993). Comunidades imaginadas: reflexiones sobre el origen y la difusión del nacionalismo (E. L. Suárez, trans.). México: Fondo de Cultura Económica.

Appadurai, A. (1996). Modernity at large: cultural dimensions of globalization. Minneapolis, MN: University of Minnesota Press.

Appiah, K. A. (2006). Cosmopolitanism: ethics in a world of strangers. New York: W.W. Norton \& Co.

Barnouw, E. (1993). Documentary: a history of the non-fiction film. Oxford: Oxford University Press.

De los Reyes, A. (1995). "Gabriel Veyre y Fernand Bon Bernard, representantes de los hermanos Lumière en México". En: Anales del Instituto de Investigaciones Estéticas, 17(67), 119-137. doi:10.22201/iie.18703062e.1995.67.1749.

Esfandiary, S. (2012). Iranian cinema and globalization: national, transnational, and Islamic dimensions. Bristol: Intellect.

Ezra, E. y Rowden, T. (2006). “General introduction: what is transnational cinema?”. En: Transnational cinema: the film reader (pp. 1-12). London: Routledge.

Festival de Cannes (n.d.). About the festival: history of the festival. Recuperado el 26 de noviembre de 2016 de http:/ /www.festival-cannes.com/en/about/aboutFestivalHistory.html.

Festival Internacional de Cine Documental de la Ciudad de México (2016). Catálogo del 11 Festival Internacional de Cine Documental de la Ciudad de México. Ciudad de México.

"Festival Internacional de Cine UNAM" (n.d.). Ediciones anteriores. Recuperado el 28 de noviembre de 2016 de http://www.ficunam.org/ediciones-anteriores/.

FIAPF-International Federation of Film Producers Associations (2016). FIAPF-Competitive Feature Film Festivals. Recuperado el 26 de noviembre de 2016 de http://www.fiapf.org/intfilmfestivals_sites.asp.

Follows, S. (2013, August 19). How many film festivals are there in the world? Recuperado el 26 de noviembre de 2016 de https://stephenfollows.com/many-film-festivals-are-in-the-world/.

Habermas, J. (1991). The structural transformation of the public sphere an inquiry into a category of bourgeois society (T. Burger, trans.). Cambridge, MA: MIT Press.

Hardy, C. y Maguire, S. (2010). \#Discourse, field-configuring events, and change in organizations and institutional fields: narratives of DDT and the Stockholm convention". En: The Academy of 
Management Journal, 53(6), 1365-1392. Recuperado el 26 de noviembre de 2016 de http://www.jstor.org/stable/29780263.

Instituto Mexicano de Cinematografía (2017). Anuario estadístico de cine mexicano 2016. Ciudad de México: IMCINE.

Internationale Filmfestspiele Berlin (n.d.). 1st Berlin International Film Festival June 6-17, 1951. Recuperado el 26 de noviembre de 2016 de http://www.berlinale.de/en/archiv/jahresarchive/1951/01_jahresblatt_1951/01_Jahresblatt_1 951.html.

Iordanova, D. y Cheung, R. (eds.) (2010). Film festival yearbook 2: film festivals and imagined communities. St. Andrews: St. Andrews Film Studies.

La Biennale di Venezia (n.d.). La Biennale di Veneria-The 30s. Recuperado el 25 de noviembre de 2016 de http://www.labiennale.org/en/cinema/history/the30s.html?back=true.

Naficy, H. (2001). An accented cinema: exilic and diasporic filmmaking. Princeton: Princeton University Press.

Rhyne, R. (2009). "Film festival circuits and stakeholders". En: D. Iordanova (ed.), Film festival yearbook 1: the festival circuit (pp. 9-22). St. Andrews: St. Andrews Film Studies.

Ronk, L. y Rothman, L. (2013, May 13). See photos of the first ever Cannes Film Festival. Recuperado el 26 de noviembre de http://time.com/3843724/first-cannes-history/.

Valck, M. D. (2007). Film festivals: from European geopolitics to global cinephilia. Amsterdam: Amsterdam University Press.

Wong, C. H. (2016). "Publics and counterpublics. Rethinking film festivals as public spheres". En: Valck M. D., Kredell B. y Loist S. (eds.), Film festivals history, theory, method, practice (pp. 83-98). London; New York, NY: Routledge. 